Rapi d Detect i on of I nt racel I ul ar p47phox and p67phox by $\mathrm{Fl}$ ow Cyt omet ry; Usef ul Screeni ng Test s for Chroni c Granul onat ous Di sease

\begin{tabular}{|c|c|}
\hline 著者 & $\begin{array}{l}\text { Wada Tai zo, Mur aoka Nasahi ro, Toma Tomoko, } \\
\text { I mai Tsuy oshi, Shi gemur a Tomnar i, Agemat su } \\
\text { Kazunaga, Har aguchi Kohei, Mri uchi H r oyuki, } \\
\text { Oh- i shi Tsut oma, Ki t oh Toshi yuki, Ohar a Osamu, } \\
\text { Mor i o Tomohi ro, Yachi e Aki hi ro }\end{array}$ \\
\hline $\begin{array}{l}\text { jour nal or } \\
\text { publ i cat } i \text { on } \mathrm{title}\end{array}$ & Journal of $\mathrm{Cl}$ i ni cal I mminol ogy \\
\hline vol une & 33 \\
\hline nunber & 4 \\
\hline page $r$ ange & $857-864$ \\
\hline year & $2013-05-01$ \\
\hline URL & ht t p: //hdl . handl e. net /2297/33426 \\
\hline
\end{tabular}




\title{
Rapid detection of intracellular p47phox and p67phox by flow cytometry; useful screening tests for chronic granulomatous disease
}

\author{
Taizo Wada, ${ }^{1}$ Masahiro Muraoka, ${ }^{1}$ Tomoko Toma, ${ }^{1}$ Tsuyoshi Imai, ${ }^{2}$ Tomonari \\ Shigemura, ${ }^{3}$ Kazunaga Agematsu, ${ }^{3}$ Kohei Haraguchi, ${ }^{4}$ Hiroyuki Moriuchi, ${ }^{4}$ \\ Tsutomu Oh-ishi, ${ }^{5}$ Toshiyuki Kitoh, ${ }^{6}$ Osamu Ohara, ${ }^{7}$ Tomohiro Morio, ${ }^{8}$ and Akihiro \\ Yachie $^{1}$
}

Institutional affiliations:

${ }^{1}$ Department of Pediatrics, School of Medicine, Institute of Medical, Pharmaceutical and Health Sciences, Kanazawa University, Kanazawa, Japan; ${ }^{2}$ Department of Pediatrics, Otsu Red-Cross Hospital, Otsu, Japan; ${ }^{3}$ Department of Pediatrics, Shinshu University School of Medicine, Matsumoto, Japan; and ${ }^{4}$ Department of Pediatrics, Nagasaki University Hospital, Nagasaki, Japan; ${ }^{5}$ Division of Infectious Diseases, Immunology, and Allergy, Saitama Children's Medical Center, Saitama, Japan; ${ }^{6}$ Department of Pediatrics, Aichi Medical University, Nagakute, Japan; ${ }^{7}$ Kazusa DNA research Institution, Chiba, Japan; ${ }^{8}$ Department of Pediatrics, Tokyo Medical and Dental University, Tokyo, Japan.

Correspondence to: Taizo Wada, MD, PhD

Department of Pediatrics, School of Medicine, Institute of Medical, Pharmaceutical and Health Sciences, Kanazawa University 13-1 Takaramachi, Kanazawa 920-8641, Japan Phone: +81-76-265-2313

Fax: +81-76-262-1866

E-mail: taizo@staff.kanazawa-u.ac.jp

Running short title: Flow cytometry for p47phox and p67phox 


\begin{abstract}
Chronic granulomatous disease (CGD) is caused by defects of NADPH oxidase. The diagnosis of CGD can be made by analysis of NADPH oxidase activity, however, identification of the CGD subgroups is required before performing mutation analysis. The membrane-bound subunits, gp91phox and p22phox, can be quickly analyzed by flow cytometry, unlike the cytosolic components, p47phox and p67phox. We evaluated the feasibility of flow cytometric detection of p47phox and p67phox with specific monoclonal antibodies in two patients with p47phox deficiency and 7 patients with p67phox deficiency. Consistent with previous observations, p47phox and p67phox were expressed in phagocytes and B cells, but not in T or natural killer cells, from normal controls. In contrast, patients with p47phox and p67phox deficiency showed markedly reduced levels of p47phox and p67phox, respectively. These techniques will be useful to rapidly assess the expression of the cytosolic components, p47phox and p67phox, and represents important secondary screening tests for CGD.
\end{abstract}

Keywords; chronic granulomatous disease; p47phox; p67phox; flow cytometry; screening test. 


\section{Introduction}

Chronic granulomatous disease (CGD) is a primary immunodeficiency disease of phagocytes caused by defects of nicotinamide dinucleotide phosphate (NADPH) oxidase $[1,2]$. NADPH oxidase is an enzyme responsible for the production of reactive oxygen species that are needed to kill pathogenic bacteria and fungi. Patients with CGD have increased susceptibility to infections, as well as hyperinflammation and granuloma formation at sites of infection [3]. The NADPH oxidase is a multicomponent system including a membrane-bound flavocytochrome b558, comprised of gp91phox and p22phox, cytosolic components, comprised of p40phox, p47phox, and p67phox, and a small GTP-binding protein comprised of Rac1 or Rac2 [1,2]. About $70 \%$ of CGD cases are caused by mutations in the $C Y B B$ gene that encodes gp91phox and is located at Xp21.1 [4]. The remaining 30\% of cases include four other subgroups of the disease, all of which are inherited in an autosomal recessive manner [1, 2]. Mutations in the NCF1 gene cause $\mathrm{p} 47$ phox deficiency, the second most common subtype of CGD, which accounts for $25 \%$ of CGD patients. The other cases occur due to mutations in the NCF2, $C Y B A$, or NCF4 genes that encode p67phox, p22phox, or p40phox, respectively. To date, p40phox deficiency has only been reported in one individual [5].

A diagnosis of CGD can be achieved by measurement of neutrophil superoxide production via NADPH oxidase. The most recognized test is the nitroblue tetrazolium test, which is based on visual inspection of phagocytes. Because of its high reliability and sensitivity, the dihydrorhodamine (DHR) assay using flow cytometry has largely replaced the nitroblue tetrazolium test in many laboratories [6]. Despite the need for specific 
technical skills, the DHR assay is able to distinguish between patients with absent to greatly diminished production of superoxide, which is commonly observed in males with $\mathrm{X}$-linked CGD and patients with residual superoxide production, which is frequently observed in autosomal recessive and variant X-linked CGD [1, 2]. However, further identification of CGD subgroups is necessary before genetic analysis, which is often labor-intensive and time-consuming. The membrane-bound subunits, gp91phox and p22phox, can be analyzed by flow cytometry using monoclonal antibodies (mAbs), such as 7D5 that identifies the extracellular domain of flavocytochrome b558 [7, 8]. In contrast, the cytosolic components, p47phox and p67phox, are usually investigated by immunoblot analysis that requires a large sample of blood and takes longer to perform. We therefore assessed the feasibility of flow cytometric analysis of intracellular p47phox and p67phox expression and demonstrate its usefulness as a secondary screening test for CGD. 


\section{Materials and methods}

\section{Patients}

We studied 9 affected patients with autosomal recessive CGD: 2 with p47phox deficiency and 7 with p67phox deficiency. All patients but p67-4 were born to nonconsanguineous Japanese parents. We also evaluated 3 patients with X-linked CGD (gp91phox deficiency) and 10 healthy adult volunteers. Case presentations of patient p471 and p47-2 and the sibling cases of p67-1.1 and p67-1.2 have been reported elsewhere [9, 10]. Patients p67-2.1 and p67-2.2 were also sibling cases. Approval for the study was obtained from the Human Research Committee of Kanazawa University Graduate School of Medical Science, and informed consent was obtained in accordance with the Declaration of Helsinki.

\section{Flow cytometry}

For the analysis of p47phox and p67phox expression, peripheral blood mononuclear cells (PBMCs) were isolated by Ficoll-Hypaque gradient centrifugation from patients and controls immediately after blood collection or after overnight shipment at ambient temperature. Granulocytes were recovered from the pellet of the gradient after lysis of any erythrocytes. PBMCs were stained for cell-surface antigens before cell membrane permeabilization using the following mAbs: fluorescein isothiocyanateconjugated anti-CD14 and anti-CD56; phycoerythrin-Cy5-conjugated anti-CD20 and anti-CD3 (all from Becton Dickinson, San Diego, CA). Granulocytes were stained with fluorescein isothiocyanate-conjugated anti-CD16b mAb (Beckman Coulter, Fullerton, 
CA). After washing, cells were fixed and permeabilized with Cytofix/Cytoperm Plus kit (Becton Dickinson) and were incubated with anti-p47phox (clone 1, Becton Dickinson), anti-p67phox mAb (clone D-6, Santa Cruz Biotechnology Inc, Santa Cruz, CA) or purified mouse $\mathrm{IgG} 1$ (Becton Dickinson) at $4^{\circ} \mathrm{C}$ for $20 \mathrm{~min}$. Cells were then reacted with phycoerythrin-conjugated anti-mouse IgG1 (Southern Biotech, Birmingham, AL) at $4^{\circ} \mathrm{C}$ for $20 \mathrm{~min}$. Stained cells were analyzed with a FACSCalibur flow cytometer using CellQuest software (BD Bioscience, Tokyo, Japan) [11]. Because the anti-p47phox and anti-p67phox mAbs belong to the mouse IgG1 subclass, all antibodies for surface staining were chosen from mouse IgG2 or IgM to avoid cross-reaction. For analysis of gp91phox and p22phox, whole blood was stained with 7D5 mAb (MBL, Nagoya, Japan).

\section{Analysis of the production of reactive oxygen species}

Peripheral blood was loaded with $1 \mu \mathrm{M}$ of DHR 123 at $37^{\circ} \mathrm{C}$ for $5 \mathrm{~min}$, and stimulated with $100 \mathrm{ng} / \mathrm{mL}$ of phorbol myristate acetate at $37^{\circ} \mathrm{C}$ for $30 \mathrm{~min}$. After lysis of erythrocytes, production of reactive oxygen species of granulocytes was quantified by measuring intracellular rhodamine using flow cytometry, as previously described $[9,12]$.

\section{Mutation analysis of NCF1 and NCF2}

DNA was extracted from blood samples using standard methods. The $N C F 1$ and NCF2 genes were amplified from specific primers as previously described [9].

Sequencing was performed on purified polymerase chain reaction products using the ABI Prism BigDye Terminator Cycle sequencing kit on an ABI 310 or 3100 automated sequencer (Applied Biosystems, Foster, CA) [13]. 


\section{Results}

\section{Mutation analysis and ROS production}

Table 1 presents the clinical and sequencing data of the patients. Patients p67-2.1 and p67-2.2 were compound heterozygotes bearing Gln260X and Arg395Trp mutations in NCF2. The former is a novel nonsense mutation. Two distinct NCF2 mutations, Tyr394Asp and Asp408fs, were demonstrated in patient p67-3. The effect of the novel missense mutation Tyr394Asp was evaluated using the web-based analysis tool, Mutation@A Glance (http://rapid.rcai.riken.jp/mutation/) [14], and was found to be deleterious on the basis of the SIFT program [15]. Patient P67-5 was a compound heterozygote bearing Trp22X and Arg102X mutations. The former is a novel nonsense mutation.

Upon stimulation with phorbol myristate acetate, DHR-loaded neutrophils from normal controls showed significant increases in fluorescence with tight peaks. Patients with gp91phox deficiency exhibited virtually no neutrophil DHR activity. In contrast, patients with p47phox or p67phox deficiency exhibited variable activity ranging from almost none to a moderate increase in the fluorescence after stimulation with characteristic wider peaks compared with those found in gp91phox deficiency.

\section{Intracellular expression of p47phox and p67phox}

Consistent with previous observations [2], p47phox and p67phox were expressed intracellularly in phagocytes and B cells, but not in T or natural killer (NK) cells, from

normal controls (Fig. 1). This pattern of lineage-specific expression was the same as that 
observed for gp91phox expression. However, we observed a marked difference in p47phox or p67phox expression among neutrophils, monocytes and B cells, which was in contrast to the expression of gp91phox. The p47phox levels in neutrophils were relatively low compared with monocytes and B cells, whereas the p67phox levels in B cells were considerably lower compared with neutrophils and monocytes. Because neutrophils exhibited decreased viability and tended to aggregate after overnight shipment and cell isolation, we decided to use PBMCs for intracellular staining of p47phox and p67phox in clinical samples in order to avoid non-specific staining that might lead to misdiagnosis.

The patients with p47phox deficiency exhibited markedly reduced levels of p47phox expression in both monocytes and B cells (Fig. 2). Conversely, the patients' monocytes and B cells expressed p67phox at levels that were comparable to normal controls. On the other hand, the patients with p67phox deficiency exhibited considerably reduced levels of p67phox expression in monocytes and B cells (Fig. 2). Although the expression of $\mathrm{p} 47 \mathrm{phox}$ in the monocytes appeared to be marginally decreased, $\mathrm{p} 47 \mathrm{phox}$ expression in the patients' B cells was comparable to normal controls. Expression of the membrane-bound component, gp91phox, determined by 7D5 mAb, was normal in all patients with p47phox and p67phox deficiency.

\section{Expression of p47phox or p67phox in carrier parents}

To evaluate the ability of our flow cytometric analysis technique to detect carriers, we examined p47phox expression in monocytes from the parents of $\mathrm{p} 47-1$ and $\mathrm{p} 67 \mathrm{phox}$ expression in monocytes from the mother of p67-2.1 and p67-2.2 and the parents of p673, all of whom were heterozygous carriers (Fig. 3). The pattern of DHR and gp91phox 
expression from the mother of gp91-1 showed a bimodal distribution consistent with her obligate X-linked CGD carrier status. In contrast, and consistent with previous reports [2], the NADPH oxidase activities of neutrophils from carriers of the p47phox and p67phox deficiency were normal. The expression of p47phox or p67phox in their monocytes appeared to be decreased slightly, compared with normal controls (Fig. 3). 


\section{Discussion}

In the present study, we have developed practical flow cytometric assays for p47phox and p67phox. Although analysis of the expression of the individual subunits by flow cytometry has been described previously [16], our approach differs from it on two counts. First, we used commercially available mAbs that are specific for $\mathrm{p} 47 \mathrm{phox}$ and p67phox. This potential advantage may allow the assay to be widely used in many laboratories. Second, we analyzed the intracellular expression of p47phox and p67phox in monocytes and B cells, as well as in neutrophils. B cells contain all of the components of the phagocyte NADPH oxidase and generate superoxide in response to a variety of stimuli; albeit at a lower level than neutrophils [17]. Our lineage-specific analysis may provide more accurate and reliable data. Previous studies using Western blot analysis have demonstrated that $\mathrm{p} 47$ phox and p67phox expression in B cells were reduced by about 6 and 70\%, respectively, compared with neutrophils [17]. The reasons neutrophils from normal individuals exhibited lower levels of $\mathrm{p} 47 \mathrm{phox}$ compared with monocytes and B cells in our assay are presently unclear. Further studies using other anti-p47phox antibodies that recognize different epitopes will be necessary to resolve this issue.

The NADPH subunits including p47phox, p67phox and p40phox exist as a tight complex in the cytoplasm in the resting state [18]. However, loss of one of the p47phox or p67phox proteins did not generally affect the expression of the other, unlike the membrane-bound components, gp91phox and p22phox. Because gp91phox and p22phox act to stabilize each other, and the absence of either protein generally leads to downregulation of the other $[19,20]$. In fact, the $7 \mathrm{D} 5 \mathrm{mAb}$ that binds exclusively to an 
extracellular domain of gp91phox has been proven not to stain the cell surface on neutrophils deficient in p22phox, thus indicating its screening capability for both gp91phox and p22phox deficiency [8]. Therefore, the combined flow cytometric analysis of the surface staining by 7D5 mAb and our assay for intracellular p47phox and p67phox would be a valuable tool for detecting subgroups of CGD.

Mutations in the gp91phox gene cause X-linked CGD and account for approximately $70 \%$ of all cases [4]. The remaining $30 \%$ are due to mutations in the other subunit and are inherited in an autosomal recessive manner [1]. In Japan, p47phoxdeficient CGD has been documented in relatively few patients, unlike Western countries [21]. Because of the infrequency of such diseases, our study was limited to include a small number of patients, in particular, those with p47phox deficiency. However, the vast majority of patients with p47phox deficiency carry the homozygous 2-bp deletion in the NCF1 gene, which was also detected in our patients. This mutation results from recombination events between the wild-type gene and the pseudogene [22, 23]. Patients with this mutation have been reported to exhibit undetectable levels of p47phox protein expression [23], which was consistent with our results. On the other hand, although a variety of mutations in the NCF2 gene have been demonstrated in patients with p67phox deficiency, the p67phox protein appears to be undetectable by Western blot analysis in most cases [23]. Interestingly, the p67phox protein was absent in patients p67-1.1, p671.2, p67-2.1, p67-2.2, p67-4 and p67-5, whereas residual p67phox expression was detected in patient p67-3 who exhibited the significant remaining NADPH oxidase activity. It should be noted that there are mutations in the $N C F 1$ or $N C F 2$ genes that leave the protein expression intact but destroy the enzymatic activity [23]. In such cases, albeit 
rare, our flow cytometric analysis of protein expression as well as Western blot analysis cannot contribute to identification of the CGD subgroups, and mutation analysis is required. Further investigations will be required to assess the sensitivity and limitations of the assay and its utility in determining the phenotype-genotype correlation.

Most female carriers of X-linked CGD can be identified by flow cytometry. A mosaic pattern of oxidase-positive and -negative neutrophils from the basis of the DHR assay or analysis of gp91phox expression is observed due to random X-chromosome inactivation. In contrast, the detection of carriers of autosomal recessive CGD is usually performed by genetic analysis. It is well known that the NADPH oxidase activity is normal in obligate carriers [2]. The expression of $\mathrm{p} 47 \mathrm{phox}$ and $\mathrm{p} 67 \mathrm{phox}$ proteins, assessed by Western blot analysis, has also been reported to likely be normal in carriers of p47phox and p67phox deficiency, respectively [2]. Our flow cytometric analysis demonstrated slightly decreased expression of p47phox and p67phox in monocytes from obligate carriers of p47phox and p67phox deficiency, respectively, compared with normal controls. However, these subtle differences of protein expression do not allow the detection of carriers in the clinical settings. Therefore, genetic testing remains appropriate for identification of carriers of autosomal recessive CGD.

In summary, our study demonstrated rapid and sensitive detection of intracellular p47phox and p67phox by flow cytometry, which is useful as a secondary screening test for CGD. This technique would be also valuable in the evaluation of chimerism in patients treated with stem cell transplantation or gene therapy. 


\section{Acknowledgments}

We thank Dr. Fabio Candotti for insightful discussions, and Ms Harumi Matsukawa, Ms. Shizu Kouraba and Ms. Miho Nishio for their excellent technical assistance. This work was supported by a grant from Morinaga Houshikai, Tokyo; a Grant-in-Aid for Scientific Research from the Ministry of Education, Culture, Sports, Science and Technology of Japan; and a grant from the Ministry of Health, Labour, and Welfare of Japan, Tokyo.

\section{Conflict of Interest}

The authors declare that they have no conflict of interest. 


\section{References}

1. Holland SM. Chronic granulomatous disease. Clin Rev Allergy Immunol. 2010;38(1):3-10. doi:10.1007/s12016-009-8136-z.

2. Roos D, kuijpers TW, Curnutte JT. Chronic granulomatous disease. Second ed. Primary Immunodeficiency Diseases. New York: Oxford Universtiy Press; 2007. 3. Rosenzweig SD. Inflammatory manifestations in chronic granulomatous disease (CGD). J Clin Immunol. 2008;28 Suppl 1:S67-72 . doi:10.1007/s10875-007-9160-5.

4. Roos D, Kuhns DB, Maddalena A, Roesler J, Lopez JA, Ariga T et al. Hematologically important mutations: X-linked chronic granulomatous disease (third update). Blood Cells Mol Dis. 2010;45(3):246-65. doi:10.1016/j.bcmd.2010.07.012.

5. Matute JD, Arias AA, Wright NA, Wrobel I, Waterhouse CC, Li XJ et al. A new genetic subgroup of chronic granulomatous disease with autosomal recessive mutations in p40 phox and selective defects in neutrophil NADPH oxidase activity. Blood. 2009;114(15):3309-15. doi:10.1182/blood-2009-07-231498.

6. Vowells SJ, Fleisher TA, Sekhsaria S, Alling DW, Maguire TE, Malech HL. Genotype-dependent variability in flow cytometric evaluation of reduced nicotinamide adenine dinucleotide phosphate oxidase function in patients with chronic granulomatous disease. J Pediatr. 1996;128(1):104-7.

7. Nakamura M, Murakami M, Koga T, Tanaka Y, Minakami S. Monoclonal antibody 7D5 raised to cytochrome b558 of human neutrophils: immunocytochemical detection of the antigen in peripheral phagocytes of normal subjects, patients with chronic granulomatous disease, and their carrier mothers. Blood. 1987;69(5):1404-8. 
8. Burritt JB, DeLeo FR, McDonald CL, Prigge JR, Dinauer MC, Nakamura M et al. Phage display epitope mapping of human neutrophil flavocytochrome b558.

Identification of two juxtaposed extracellular domains. J Biol Chem. 2001;276(3):205361. doi:10.1074/jbc.M006236200.

9. Honda F, Hane Y, Toma T, Yachie A, Kim ES, Lee SK et al. Transducible form of p47phox and p67phox compensate for defective NADPH oxidase activity in neutrophils of patients with chronic granulomatous disease. Biochem Biophys Res Commun. 2012;417(1):162-8. doi:10.1016/j.bbrc.2011.11.077.

10. Kabuki T, Kawai T, Kin Y, Joh K, Ohashi H, Kosho T et al. [A case of Williams syndrome with p47-phox-deficient chronic granulomatous disease]. Nihon Rinsho Meneki Gakkai Kaishi. 2003;26(5):299-303.

11. Wada T, Schurman SH, Otsu M, Garabedian EK, Ochs HD, Nelson DL et al. Somatic mosaicism in Wiskott--Aldrich syndrome suggests in vivo reversion by a DNA slippage mechanism. Proc Natl Acad Sci U S A. 2001;98(15):8697-702. doi:10.1073/pnas.151260498.

12. Kasahara Y, Iwai K, Yachie A, Ohta K, Konno A, Seki H et al. Involvement of reactive oxygen intermediates in spontaneous and CD95 (Fas/APO-1)-mediated apoptosis of neutrophils. Blood. 1997;89(5):1748-53.

13. Asai E, Wada T, Sakakibara Y, Toga A, Toma T, Shimizu T et al. Analysis of mutations and recombination activity in RAG-deficient patients. Clin Immunol. 2011;138(2):172-7. doi:10.1016/j.clim.2010.11.005. 
14. Hijikata A, Raju R, Keerthikumar S, Ramabadran S, Balakrishnan L, Ramadoss SK et al.Mutation@A Glance: an integrative web application for analysing mutations from human genetic diseases. DNA Res. 2010;17(3):197-208. doi:10.1093/dnares/dsq010. 15. Ng PC, Henikoff S. SIFT: Predicting amino acid changes that affect protein function. Nucleic Acids Res. 2003;31(13):3812-4.

16. Yu G, Hong DK, Dionis KY, Rae J, Heyworth PG, Curnutte JT et al. Focus on FOCIS: the continuing diagnostic challenge of autosomal recessive chronic granulomatous disease. Clin Immunol. 2008;128(2):117-26. doi:10.1016/j.clim.2008.05.008. 17. Dusi S, Nadalini KA, Donini M, Zentilin L, Wientjes FB, Roos D et al. Nicotinamide-adenine dinucleotide phosphate oxidase assembly and activation in EBVtransformed B lymphoblastoid cell lines of normal and chronic granulomatous disease patients. J Immunol. 1998;161(9):4968-74.

18. Lapouge K, Smith SJ, Groemping Y, Rittinger K. Architecture of the p40-p47p67phox complex in the resting state of the NADPH oxidase. A central role for p67phox. J Biol Chem. 2002;277(12):10121-8. doi:10.1074/jbc.M112065200. 19. Parkos CA, Dinauer MC, Jesaitis AJ, Orkin SH, Curnutte JT. Absence of both the $91 \mathrm{kD}$ and $22 \mathrm{kD}$ subunits of human neutrophil cytochrome $\mathrm{b}$ in two genetic forms of chronic granulomatous disease. Blood. 1989;73(6):1416-20.

20. Verhoeven AJ, Bolscher BG, Meerhof LJ, van Zwieten R, Keijer J, Weening RS et al. Characterization of two monoclonal antibodies against cytochrome b558 of human neutrophils. Blood. 1989;73(6):1686-94. 
21. Ishibashi F, Nunoi H, Endo F, Matsuda I, Kanegasaki S. Statistical and mutational analysis of chronic granulomatous disease in Japan with special reference to gp91-phox and p22-phox deficiency. Hum Genet. 2000;106(5):473-81.

22. Gorlach A, Lee PL, Roesler J, Hopkins PJ, Christensen B, Green ED et al. A p47-

phox pseudogene carries the most common mutation causing p47-phox- deficient chronic granulomatous disease. J Clin Invest. 1997;100(8):1907-18. doi:10.1172/JCI119721.

23. Roos D, Kuhns DB, Maddalena A, Bustamante J, Kannengiesser C, de Boer M et al. Hematologically important mutations: the autosomal recessive forms of chronic granulomatous disease (second update). Blood Cells Mol Dis. 2010;44(4):291-9. doi:10.1016/j.bcmd.2010.01.009. 
Table 1 Clinical and sequencing data

Subjects Age ${ }^{\mathrm{a}}$ Clinical features Gene Nucleotide Effect mutation

\begin{tabular}{|c|c|c|c|c|c|}
\hline $\mathrm{p} 47-1$ & $31 \mathrm{y}$ & $\begin{array}{l}\text { Skin infections, } \\
\text { otitis, colitis }\end{array}$ & $N C F 1$ & 73_74delGT ${ }^{\mathrm{d}}$ & Tyr26fs \\
\hline $\mathrm{p} 47-2$ & $13 y$ & $\begin{array}{l}\text { BCGitis } \\
\text { Williams syndrome }\end{array}$ & $N C F 1$ & $\begin{array}{l}\text { 73_74delGT } \\
\text { 7q11.23 deletion }\end{array}$ & Tyr26fs \\
\hline p67-1.1 ${ }^{\mathrm{b}}$ & $8 \mathrm{y}$ & $\begin{array}{l}\text { Perianal abscess, } \\
\text { lymphadenitis }\end{array}$ & $N C F 2$ & $1223 \mathrm{delA}^{\mathrm{d}}$ & Asp408fs \\
\hline $\mathrm{p} 67-1.2^{\mathrm{b}}$ & $2 y$ & Perianal abscess & $N C F 2$ & $1223 \mathrm{delA}^{\mathrm{d}}$ & Asp408fs \\
\hline p67-2. $1^{\mathrm{c}}$ & $1 \mathrm{mo}$ & $\begin{array}{l}\text { Aspergillus } \\
\text { pneumonia }\end{array}$ & $N C F 2$ & $\begin{array}{l}778 \mathrm{C}>\mathrm{T} \\
1183 \mathrm{C}>\mathrm{T}\end{array}$ & $\begin{array}{l}\text { Gln260X } \\
\text { Arg395Trp }\end{array}$ \\
\hline $\mathrm{p} 67-2.2^{\mathrm{c}}$ & $3 y$ & Sepsis & $N C F 2$ & $\begin{array}{l}778 \mathrm{C}>\mathrm{T} \\
1183 \mathrm{C}>\mathrm{T}\end{array}$ & $\begin{array}{l}\text { Gln260X } \\
\text { Arg395Trp }\end{array}$ \\
\hline p67-3 & $6 \mathrm{mo}$ & $\begin{array}{l}\text { Aspergillus } \\
\text { pneumonia }\end{array}$ & $N C F 2$ & $\begin{array}{l}1180 \mathrm{~T}>\mathrm{G} \\
1223 \mathrm{delA}\end{array}$ & $\begin{array}{l}\text { Tyr394Asp } \\
\text { Asp408fs }\end{array}$ \\
\hline p67-4 & $10 \mathrm{~m}$ & BCGitis & $N C F 2$ & $304 \mathrm{C}>\mathrm{T}^{\mathrm{d}}$ & $\operatorname{Arg} 102 X$ \\
\hline p67-5 & $5 y$ & $\begin{array}{l}\text { BCGitis } \\
\text { lymphadenitis }\end{array}$ & $N C F 2$ & $\begin{array}{l}66 \mathrm{G}>\mathrm{A} \\
304 \mathrm{C}>\mathrm{T}\end{array}$ & $\begin{array}{l}\text { Trp22X } \\
\text { Arg102X }\end{array}$ \\
\hline
\end{tabular}

${ }^{a}$ Data at the time of sample collection.

${ }^{b, c}$ Sibling cases.

${ }^{\mathrm{d}}$ Homozygous mutation. 


\section{Figure Legends}

Figure 1 Expression of p47phox, p67phox and gp91phox in blood leukocyte populations from normal individuals.

Shown are the results of intracellular expression of p47phox (top) and p67phox (middle), and surface expression of gp91phox analyzed by 7D5 mAb (bottom) in CD16b neutrophils, $\mathrm{CD}_{14}{ }^{+}$monocytes, $\mathrm{CD} 3^{+} \mathrm{T}, \mathrm{CD} 20^{+} \mathrm{B}$, and $\mathrm{CD} 56^{+} \mathrm{NK}$ cells from a healthy control. Thin lines indicate control Ab; thick lines represent mAbs specific for the NADPH subunits.

Figure 2 Analysis of DHR and expression of p47phox, p67phox and gp91phox in CGD patients.

In the DHR assay, granulocytes were analyzed using DHR 123 as a fluorescent probe before (thin lines) and after (thick lines) stimulation with phorbol myristate acetate. Expression of gp91phox in granulocytes, as assessed using 7D5, and expression of p47phox and p67phox in $\mathrm{CD} 14^{+}$monocytes and CD20 $0^{+} \mathrm{B}$ cells are shown.

\section{Figure 3 DHR assay and expression of p47phox or p67phox in carrier parents.}

Rhodamine expression in unstimulated and phorbol myristate acetate-stimulated granulocytes obtained from obligate carriers. Expression of gp91phox analyzed using 7D5 in granulocytes and the expression of p47phox or p67phox in $\mathrm{CD} 14^{+}$monocytes are shown. 
Figure 1

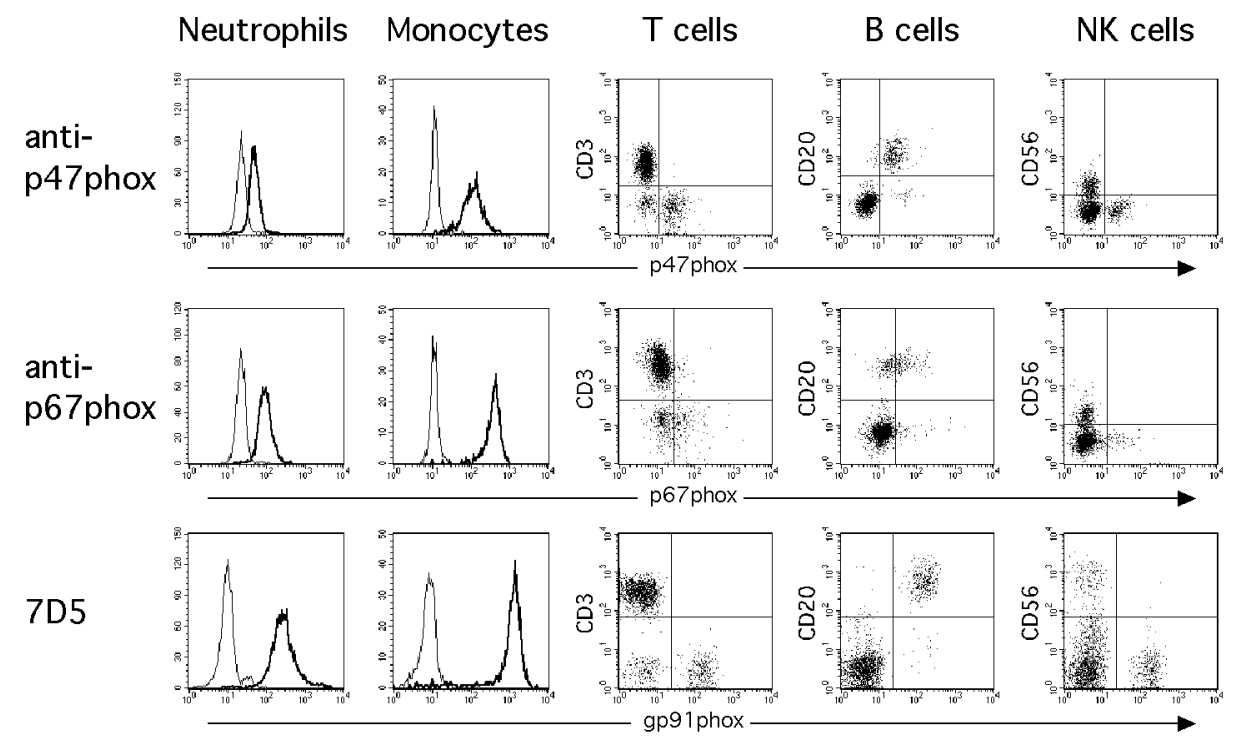


Figure 2

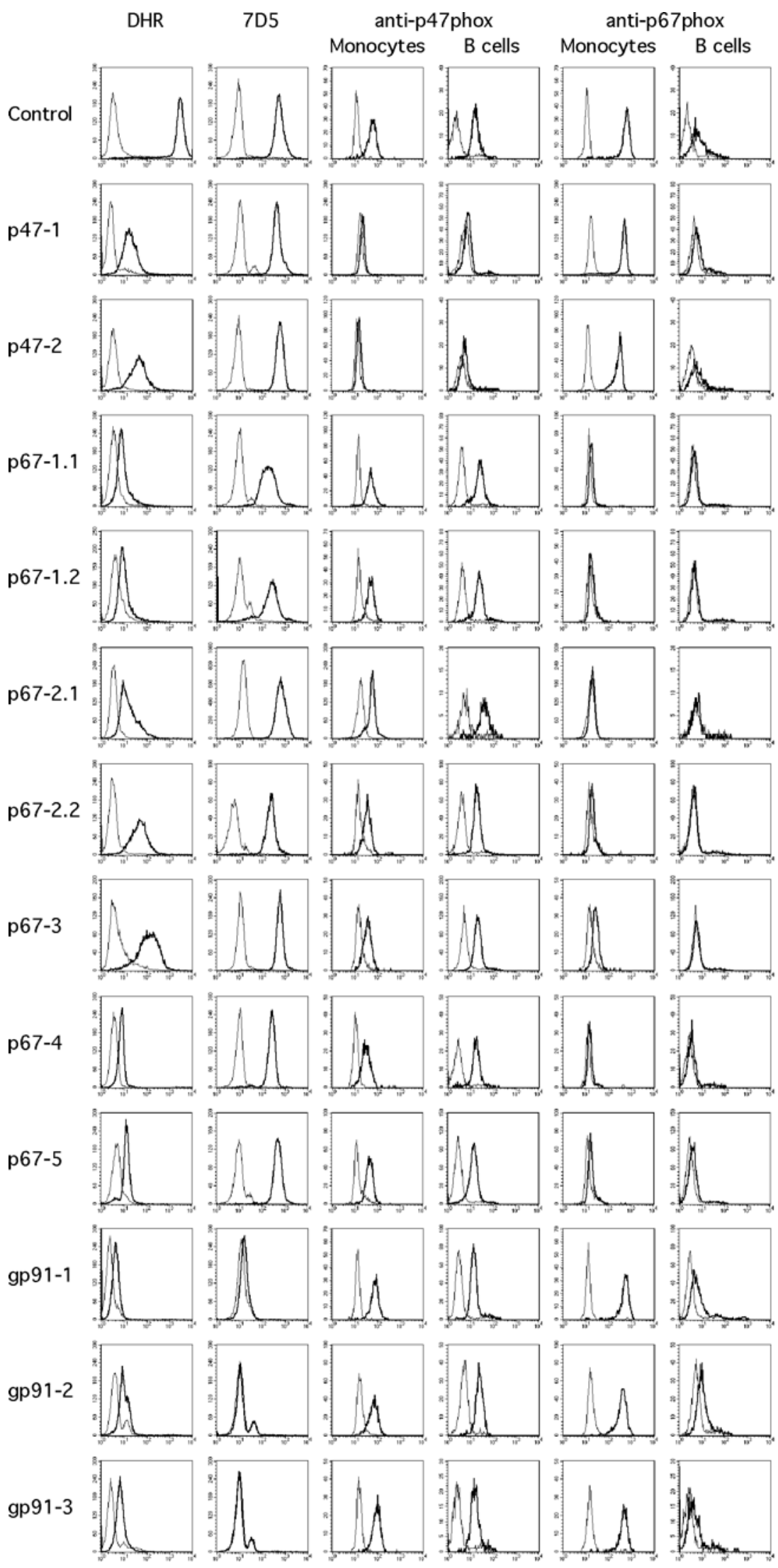


Figure 3

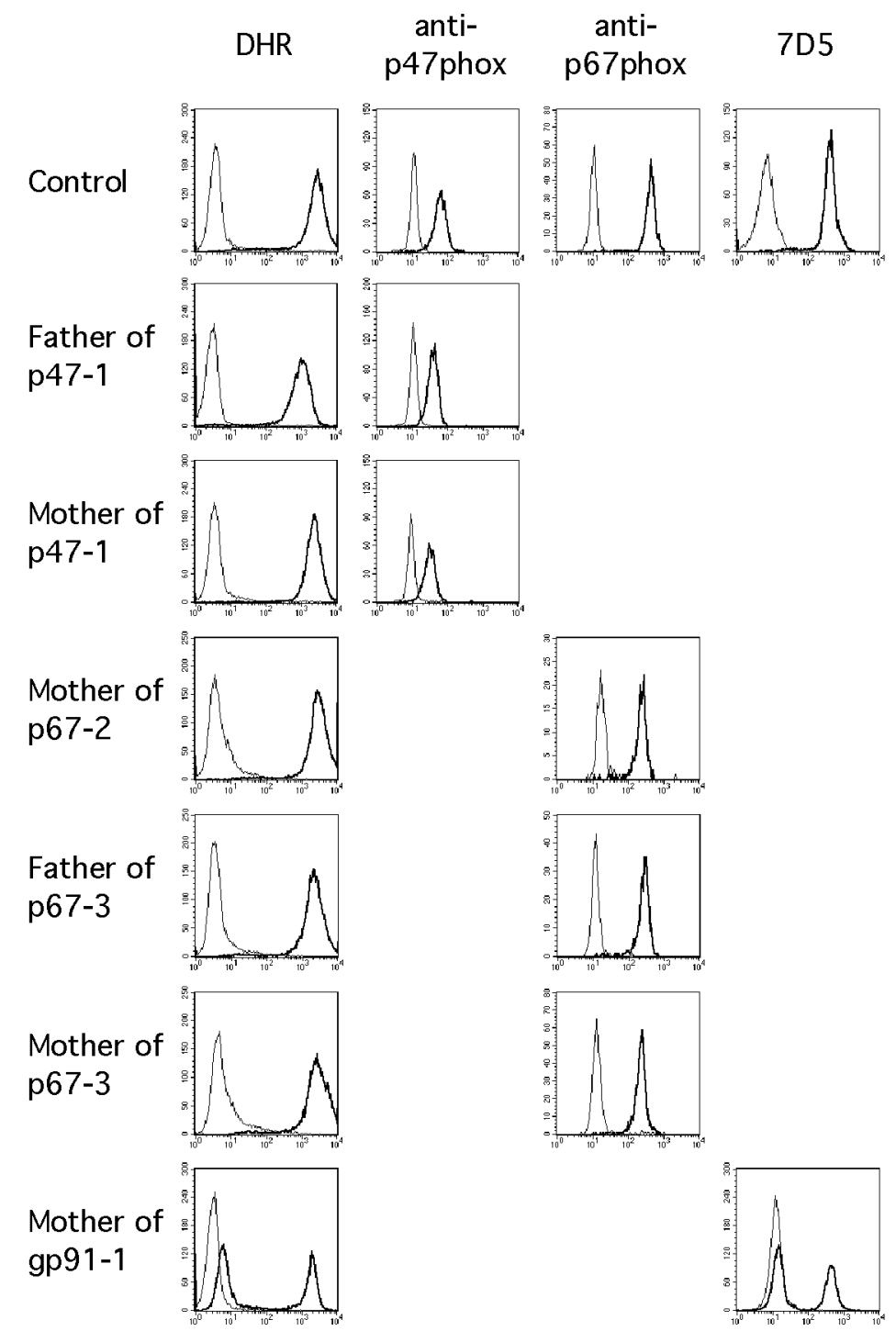

